Важное место среди кровоостанавливающих и ранозаживляющих средств имеют лекарственные растения и приготавливаемые препараты из них. Они очень эффективны в лечении ран и кровотечений.

Ярко выраженным кровоостанавливающим эффектом обладает лекарственное растение Лагохилус опьяняющий. Листья данного лекарственного растения содержат лагохилин, эфирные масла - 0,04\%, дубильные вещества - $15 \%$, органические кислоты, каротин, витамины С и К.

Горец перечный известен своими целебными свойствами еще во времена Парацельса. Но как кровоостанавливающее средство он начал применяться с начала 20-го века. В траве горца находятся дубильные вещества, флавонольные производные (рутин, гиперозид, рамназин и др.), эфирные масла, органические кислоты, витамины С и К.

Хорошим кровоостанавливающим действием обладает Калина обыкновенная. Кровоостанавливающий эффект калины обусловлен тем, что в коре данного растения содержится достаточное количество витамина К, гликозида вибурнина, сложные эфиры и дубильные вещества. Также помимо кровоостанавливающего действия, кора калины обладает спазмолитическим, успокаивающим и вяжущим действием.

Пастушья сумка содержит значительное количество витамина К, аскорбиновой кислоты, амины: холин, ацетилхолин, тирамин и гистамин.

Крапива двудомная очень распространена и легкодоступна. Состав листьев крапивы очень богат витамином $\mathrm{K}-0,3 \%$, витамин $\mathrm{C}-0,5 \%$, каротиноиды $-50 г$, гликозид уртицин, дубильные вещества и др. Этим составом и обусловлено его кровоостанавливающее и ранозаживляющее действие.

Также используют Плоды облепихи. Но помимо необходимых ранозаживляющих эффектов, облепиха является спазмолитическим и противовоспалительным средством. В плодах облепихи содержатся провитамин А до 10 мг\% и витамин К, дубильные вещества, кверцетин, жирное масло.

$$
* * *
$$

1. Государственная фармакопея. - 14-е изд. - М.: Медицина: Вып.1 Характеристика ЛРС

2. Государственная фармакопея: Вып.2 Общие методы анализа. Лекарственное растительное сырье. - 14-е изд. - М.: Медицина

3. Лекарственные растения. - Спб.: ООО «СЗКЭО», 2016. - 320 С.: ил. Под редакции А.Шаронов.

4. Энциклопедия лекарственных растений. - Вильнюс, UAB «Bestiary», 2018.- 224 с.: ил. Под редакцией С.Ю. Афонькин.

5. Википедия - Свободная энциклопедия \l: http:www:wikipedia.org.

6. Лекарственные растительные сборы / Л.Г. Марченко [и др.]. - СПб.: Питер, 2016. - 88 с.

\title{
Дзидзоева М.И. \\ Производство БАД. Нормативная документация. Основы технологии и контроля качества БАД
}

Северо-Осетинский государственный университет им.К.Л.Хетагурова

(Россия, Владикавказ)

doi: 10.18411/trnio-01-2022-208

\section{Аннотация}

В статье проведен анализ производства БАД. Исследована нормативная документация по заданному вопросу. Проведен анализ основных технологий и контроля качества БАД.

Ключевые слова: БАД, технология, качество, производство, формы, медицина.

\section{Abstract}

The article analyzes the production of dietary supplements. The normative documentation on the given question is investigated. The analysis of the main technologies and quality control of dietary supplements is carried out.

Keywords: dietary supplements, technology, quality, production, forms, medicine. 
Введение.

Биологически-активные добавки представляют собой активные вещества или же их композиции, которые предназначены для отдельного приема вместе с пищей или же для добавления непосредственно в пищевые продукты. По своей классификации БАД являются пищей, а не лекарством. При этом они могут использоваться для улучшения самочувствия и состояния здоровья, а также для достижения других целей в зависимости от показаний.

Необходимо учитывать, что основной проблемой законодательства Российской Федерации в настоящий момент является тот факт, что нет единой целостной системы для контроля стандартов производства и отпуска БАД. При этом регулирование осуществляется только лишь с точки зрения безопасности для покупателя, его здоровья и жизни. Эффективность, конкретный допустимый состав и иные факторы вовсе не отслеживаются, что приводит в настоящий момент к серьезной проблеме на рынке в виде появления огромного количества недобросовестных поставщиков.

Цель работы - анализ производства БАД и нормативной документации.

Материалы и методы.

Объектом исследования были биологически активные добавки.

Методы исследования: аналитический метод, обзорный метод.

Результаты и обсуждение.

В результате можно сделать вывод о том, что в настоящий момент сам термин биологически-активной добавки является достаточно двойственным как среди профессионального медицинского персонала, так и среди обывателей. Первая точка зрения крайне негативная. Она означает, что подобные препараты могут навредить организму своим действием, они не регулируются, а значит воздействуют на организм практически бесконтрольно. Также есть мнение о том, что прием подобных средств представляет собой пустую трату времени и денег. Вторая точка зрения представляет собой заключение о том, что это необходимая поддержка организма с помощью полезных веществ, витаминов и минералов, которые скрыты в комплексе. В результате можно частично отметить правоту обеих сторон. Основная сложность заключается в том, что присутствует огромное количество заблуждений со стороны пациентов и врачей и множество ошибок при принятии подобных биологически-активных добавок [1].

Биологически-активные добавки к пище прочно вошли в фармацевтику. Это особый разряд препаратов, которые не являются лекарственными, но при этом тщательно контролируются государством. В первую очередь необходимо выделить основные нормативные акты, на основании которых происходит производство БАД.

- Ф3 №52 рассматривает санитарно-эпидемиологическое благополучие населения и тщательно его контролирует.

- $\quad$ Ф3 №29 анализирует качество и безопасность всех пищевых продуктов, в том числе и БАД.

- Действует в этой сфере закон о защите прав потребителей РФ.

- СанПин создан отдельно о требованиях к организации производства и оборота в сфере БАД, а также о требованиях к срокам годности и хранению биологически-активных добавок.

В том случае, если речь идет об экспорте этой продукции в Российской Федерации, дополнительно необходимо учитывать технические регламенты Таможенного союза о безопасности пищевых продуктов, упаковки, а также о правилах маркировки для БАД.

Необходимо учитывать, что оборот БАД реализуется только лишь с помощью специализированных магазинов, основная направленность которых торговля диетическими продуктами, а также с помощью аптечных сетей. Отдельная розничная торговля является незаконной [2].

Дополнительный контроль качества осуществляется с помощью обязательства по государственной регистрации. Биологически-активные добавки согласно законодательству Российской Федерации, относятся именно к специализированной пищевой продукции, при 
этом она подлежит государственной регистрации. Происходит это с помощью предоставления документации в Роспотребнадзор по заявлению производителя. Необходимо предоставить само заявление, дополнительно указать в необходимой форме результаты проведенных исследований и испытаний, при этом они обязательно должны проходить в аккредитованной государством лаборатории, также могут быть приложены иные документы. Основная задача в процессе регистрации доказать соответствие конкретной продукции в виде биологичеки-активных добавок нормативной документации и ее требованиям. При этом обязательно прилагаются документы, которые свидетельствуют о назначении конкретной пищевой продукции, к ней и относятся по классификации БАД. После прохождения представленного процесса регистрации БАЛ включается в единый реестр специальной пищевой продукции и может продаваться всеми указанными в рамках законодательства способами [3].

Дополнительно необходимо обратить внимание на упаковку. Согласно законодательству в Российской Федерации на ней обязательно должна быть зафиксированная в законодательстве маркировка, в частности это.

- $\quad$ Информация о производителе и его товарный знак, если он присутствует.

- Данные о нормативной или же технической документации, на основании требований которых производится подобный продукт.

- Состав, при этом порядок ингредиентов устанавливается на основании весового или же процентного соотношения в препарате.

- Основные потребительские свойства для конкретной биологическиактивной добавки.

- $\quad$ Данные о весе или же объеме в рамках конкретной упаковке.

- Данные о противопоказаниях при их наличии, при этом дополнительно необходимо указывать возможность применения при наличии разнообразных диагнозов.

- Обязательно фиксируется на упаковке надпись о том, что биологическиактивная добавка не является лекарственным препаратом.

- Указывается дата изготовления, дополнительно необходимо отметить срок годности, речь идет о гарантийном или же конечный срок реализации на выбор производителя.

- $\quad$ Фиксируются необходимые для конкретного средства условия хранения.

- Указывается информация о регистрации препарата согласна конкретного законодательства.

- $\quad$ Необходимо предоставить полную информацию о производителе вместе с местом его расположения и контактным телефоном, по которому могут приниматься претензии покупателей.

Необходимо учитывать, что вся представленная информация обязательно должна быть на упаковке доступной к прочтению. При этом есть возможность использовать дополнительно разнообразные рекламные материалы и описание биологически-активной добавки. Однако, также стоит обратить внимание на то, что терминология экологически чистый продукт запрещена, как и любая другая, в которой нет законодательного или же научного обоснования [4].

Необходимо учитывать, что производство и оборот биологически-активных добавок с разнообразными нарушениями становится причиной административной ответственности. Также отдельно нужно отметить, что в некоторых случаях это может быть признано уголовно наказуемым деянием.

В результате можно сделать вывод о том, что процесс производства и оборота БАД представляет собой достаточно сложный процесс, который строго регулируется законодательством во всех деталях, при малейших нарушениях наступает административная 
ответственность в виде серьезных штрафов. Если же в результате нарушения повлекли вред для здоровья или жизни не исключена уголовная ответственность производителя.

Заключение.

На основании представленной информации есть возможность сделать вывод о том, что как производство, так и оборот биологически-активных добавок в Российской Федерации в настоящий момент представляют собой исключительно коммерческую основу. Дополнительно сложность заключается в достаточно распространенном маркетинге, это означает, что активное стимулирование для принятия и покупки дает дополнительный риск для потребителя, при этом никак не регулируется законодательством. Кроме того, необходимо отметить, что в этой сфере есть огромное количество недобросовестных производителей, которые нарушают законодательство и прибегают к использованию вредных или же неизученных компонентов, нарушают основные правила производства, маркировки или же оборота. Причиной этому становится недостаточная ответственность.

Административный штраф даже в крупном размере для многих коммерческих компаний не является соответствующим наказанием, чтобы не заниматься подобной деятельностью. В результате можно сделать вывод о том, что в настоящий момент необходимо дорабатывать законодательство Российской Федерации с точки зрения дополнительного контроля за производством и оборотом биологически-активных добавок, а также с точки зрения ответственности за нарушение существующих и новых основных регламентов.

$$
* * *
$$

1. Сенина М.В., Москвичева М.А. Основные элементы стратегии позиционирования БАД на фармацевтическом рынке Российской Федерации //Молодой ученый. 2019. № 25 (129). С. 391-394.

2. Антонова И.С., Веснина А.Д., Шадрин В.Г. Маркетинговое исследование рынка биологически активных добавок // Техника и технология пищевых производств. 2020. Т. 50. № 3. С. 503-514.

3. Широкова М.В. Позиционирование биологически активных добавок как основа повышения конкурентоспособности компании на фармацевтическом рынке //Молодой ученый. 2016. № 4 (108). С. 524529.

4. Шерстобитова Т.И., Сморчкова Е.Д. Тенденции развития российского фармацевтического рынка // Экономический анализ: теория и практика. 2018. Т. 17. № 7 (478). С. 1200-1210

Дзидзоева М.И.

Производство глазных лекарственных форм

Северо-Осетинский государственный университет им.К.Л.Хетагурова

(Россия, Владикавказ)

doi: 10.18411/trnio-01-2022-209

\section{Аннотация}

В представленной статье проведен анализ производства глазных лекарственных форм. Проанализирован фармакологический рынок, исследованы основные требования маркетинговой деятельности в области.

Ключевые слова: глазные формы, лекарственные формы, фармакологический рынок, кровообращение.

\section{Abstract}

The presented article analyzes the production of ocular dosage forms. The pharmacological market is analyzed, the basic requirements of marketing activities in the field are investigated.

Keywords: eye forms, dosage forms, pharmacological market, blood circulation.

Введение.

Необходимо обратить особенное внимание на производство глазных лекарственных форм. Актуальность рассмотрения этой темы обусловлена тем, что благодаря активному 